\title{
Сравнение сорбционных свойств нативного и термически модифицированного доломита по отношению к катионам железа
}

\author{
Нефедьева Т.А., Калюкова Е.Н., Благовещенская Н.В. \\ ФГБОУ ВО «Ульяновский государственный университет», Ульяновск
}

Поступила в редакцию 27.10.2016 г.

\begin{abstract}
Исследован процесс адсорбции катионов железа из растворов на природном сорбенте - доломит. Получены количественные характеристики процесса адсорбции катионов железа(III). Установлена более высокая адсорбционная способность катионов железа в комбинации с термически модифицированным доломитом по сравнению с нативным фильтрующим материалом.
\end{abstract}

Ключевые слова: адсорбция, природные фильтрующие материалы, изотермы сорбции.।

\section{Comparison of the sorption properties of native and thermally the modified dolomite in relation to the iron cations}

\author{
Nefedyeva T.A., Kaljukova E.N., Blagoveshchenskya N.V. \\ Ulyanovsk state University, Ulyanovsk
}

\begin{abstract}
Process of adsorption of cations of iron of solutions on a natural sorbent - the dolomite used in various modifications is investigated (granules, thermally processed dolomite, native dolomite). The analysis was carried out by a photometric and electrometric method by the certified techniques. Quantitative characteristics of process of adsorption of cations of iron (III) are received, value of a hydrogen indicator is defined (before contact of solution with a sorbent). In all initial solutions a hydrogen indicator lower than 7 . But at addition of thermally modified sorbent value of a hydrogen indicator grows, in this regard also extent of cleaning of cations of iron (III) increases. Ten-percentage additive of thermally modified dolomite to initial dolomite increases extent of purification of solution of $\mathrm{Fe}^{3+}$ cations practically by $100 \%$. At a research of process of adsorption of cations of iron (III) of solutions on natural sorbents a molding, diatomite, dolomite it is established that all studied natural sorbents have sorption properties in relation to cations of iron (III). In size of the adsorptive ability in relation to cations of iron (III) the natural filtering materials can be rowed: a molding $>$ diatomite $>$ dolomite (according to the previous researches). The combined sorbent - native dolomite, a molding or diatomite with additive of the filtering material of dolomite which is thermally processed natural has the increased adsorptive ability, and allows to receive higher extent of purification of solution.
\end{abstract}

Keywords: adsorption, natural filtering materials, sorption isotherms.

\section{Введение}

Увеличивающиеся масштабы производства и повышение требований к качеству воды диктуют поиск более эффективных способов удаления загрязнений из природных и сточных вод. Природные воды сильно различаются как по общему содержанию растворенных солей, так и по относительному содержанию различных ионов. Это различие может существенно отражаться на свойствах воды, важных для 
той или другой области её применения: промышленности, бытовых нужд, науки и техники. Железо придает воде неприятную красно-коричневую окраску и ухудшает ее вкус, вызывает развитие железобактерий, отложение осадка в трубопроводах и их засорение.

Содержание железа в воде питьевого качества не должно превышать значений 0.3 мг/дм ${ }^{3}$. Для подземных вод большинства регионов страны характерно превышение этих нормативов в разы и даже десятки раз. Повышенная концентрация железа вредна для организма человека. Оно может накапливаться в печени в виде коллоидных оксидов железа (гемосидирина), вредно воздействующих на клетки печени, вызывая их разрушение. Повышение содержание катионов железа в воде может принести целый ряд проблем и при бытовом, и при промышленном использовании. В некоторых случаях может очень сильно пострадать качество приготовленной еды. Поэтому задача по очистке становится очень актуальной для питьевого и бытового применения, а также для промышленного использования. Среди методов, успешно применяющихся для очистки воды от катионов железа, сорбционная очистка является одним из наиболее эффективных методов, позволяющих удалить загрязнения широкой природы практически до любой остаточной концентрации независимо от их химической устойчивости, отсутствия вторичных загрязнений и управляемости процессом. В настоящее время сорбционные методы очистки широко применяются как в технологиях водоподготовки, так и для очистки сточных вод. Все большее применение в качестве сорбентов находят природные фильтрующие материалы, с помощью которых можно как удалять вещества различной природы, так и выполнять доочистку сточных вод. Применение природных сорбентов экономически более целесообразно, что связано с их относительно невысокой стоимостью и отсутствием проблем регенерации [1-5].

\section{Эксперимент}

В работе было решено проверить, какие изменения будут происходить в растворах, содержащих катионы железа(III) при добавлении нативного и термически модифицированного доломита, и сравнить их сорбционные свойства по отношению к катионам $\mathrm{Fe}^{3+}$.

Природный доломит - осадочная карбонатная горная порода, белого, серого или другого цвета, целиком или преимущественно состоящая из породообразующего минерала класса карбонатов - $\mathrm{CaMg}\left(\mathrm{CO}_{3}\right)_{2}$.

Из природных карбонатов наибольшее применение имеют кальцит и доломит как строительные материалы, слабощелочные реагенты, для получения кальция и его производных.

Природные карбонаты: магнезит, кальцит и доломит используют для получения $\mathrm{Ca}, \mathrm{Mg}$ и их производных, и как строительные материалы. Магнезит используется как огнеупорный материал и как источник технических соединений магния. Основным компонентом природного материала магнезит является безводный карбонат магния $\mathrm{MgCO}_{3}$. Магнезит содержит примерно 48\% оксида магния (MgO). Магнезит встречается в виде белых ромбоэдрических кристаллов с желтоватым или сероватым оттенком вследствие загрязнения. Карбонат магния начинает разлагаться до $\mathrm{MgO}$ при $350^{\circ} \mathrm{C}$. Оксид кальция получают обжигом известняка при 900-1000 $\mathrm{C}$.

Использованный в работе доломит (или доломитовая крошка - ДК), являлся отходом производства предприятия, перерабатывающего природный доломит. В работе использовали доломит в виде гранул с размером зерен 1-2 мм. Анализ исходного сорбента показал, что он имеет состав $\mathrm{CaCO}_{3}{ }^{\cdot} \mathrm{MgCO}_{3}{ }^{\circ} \mathrm{MgO}$.

Нефедьева и др. / Сорбционные и хроматографические процессы. 2017. Т. 17. № 3 
При исследовании адсорбционной способности природных фильтрующих материалов статическим методом исследуемую воду с определенной концентрацией катионов железа(III) и сорбентом массой 1 г перемешивали и отфильтровывали, затем определяли концентрацию катионов железа(III) в исходном растворе и в фильтрате фотометрическим методом на фотоколориметре КФК-2 МП по стандартным методикам [6].

Сведения о сорбционных свойствах материала могут быть получены и при определении величины адсорбции. Количественно адсорбция Г определяется избытком вещества на границе фаз по сравнению с равновесным количеством данного вещества [7]. Экспериментально величину адсорбции растворенных веществ на твердом сорбенте вычисляли по уравнению:

$$
\Gamma=\frac{\left(C_{u с x}-C_{\text {равн }}\right) \cdot V_{p-p a}}{m_{\text {сорбента }}},
$$

где $\mathrm{C}_{\text {исх. }}$ - исходная концентрация катионов железа(III) в растворе, ммоль/дм³ $\mathrm{C}_{\text {равн. }}$ - равновесная концентрация катионов в растворах после процесса сорбции, ммоль/дм ${ }^{3} ; \mathrm{V}_{\text {p-ра }}$ - объем раствора, дм ${ }^{3} ; \mathrm{m}_{\text {сорбента }}$ - масса сорбента, используемого для процесса сорбции, г.

Степень очистки растворов определяли по формуле:

$$
h=\frac{\left(C_{u c x}-C_{\text {равн }}\right)}{C_{u с x}} \cdot 100(\%) \cdot
$$

Параллельно проводили опыты с термически модифицированным доломитом (ДКТ) при температуре 400-600 С или в комбинации с нативным доломитом.

\section{Обсуждение результатов}

По результатам исследований выявлено, что степень извлечения катионов железа(III) зависит от концентрации только при использовании нативного доломита. При добавлении к нативному доломиту 10\% термически модифицированного доломита или при использовании только термически обработанного сорбента, массой 0.1 г, степень извлечения катионов железа(III) практически составляла $100 \%$ или приближалась к этой величине (рис. 1). Во всех случаях остаточная концентрация катионов $\mathrm{Fe}^{3+}$ была намного меньше ПДК. Даже при исходной концентрации $200 \mathrm{мг/дм}{ }^{3}$ остаточная концентрация катионов $\mathrm{Fe}^{3+}$ составляла 0.04 мг/дм ${ }^{3}$ (раствор с ДКТ) или 0.3 мг/дм ${ }^{3}$ (раствор ДК+ДКТ).

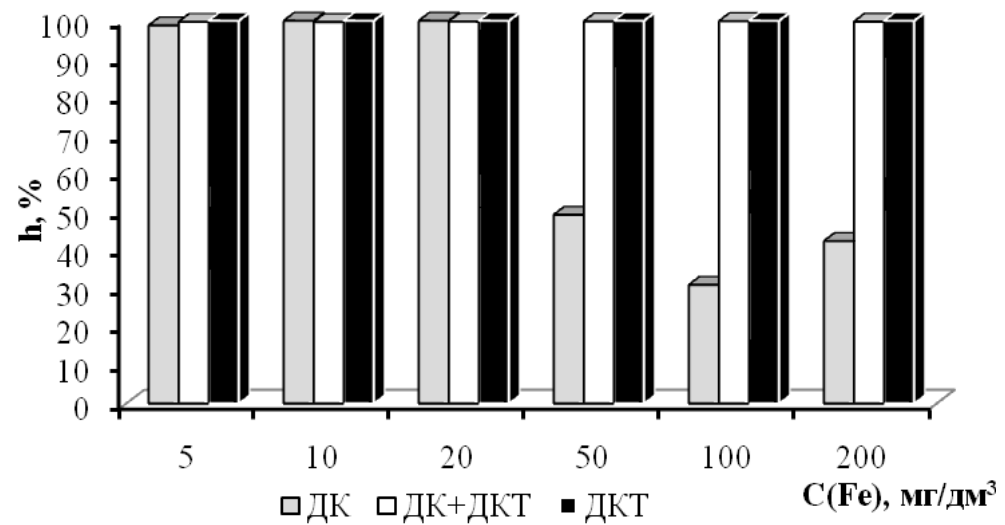

Рис. 1. Изменение степени извлечения катионов $\mathrm{Fe}^{3+}$ из растворов хлорида железа(III) в зависимости от концентрации исходного раствора и вида сорбента 
Результаты эксперимента показали, что величина адсорбции увеличивается с ростом исходной концентрации раствора (рис. 2). При добавлении к нативному доломиту $10 \%$ термически модифицированного сорбента (ДКТ) величина адсорбции катионов $\mathrm{Fe}^{3+}$ резко увеличивается.
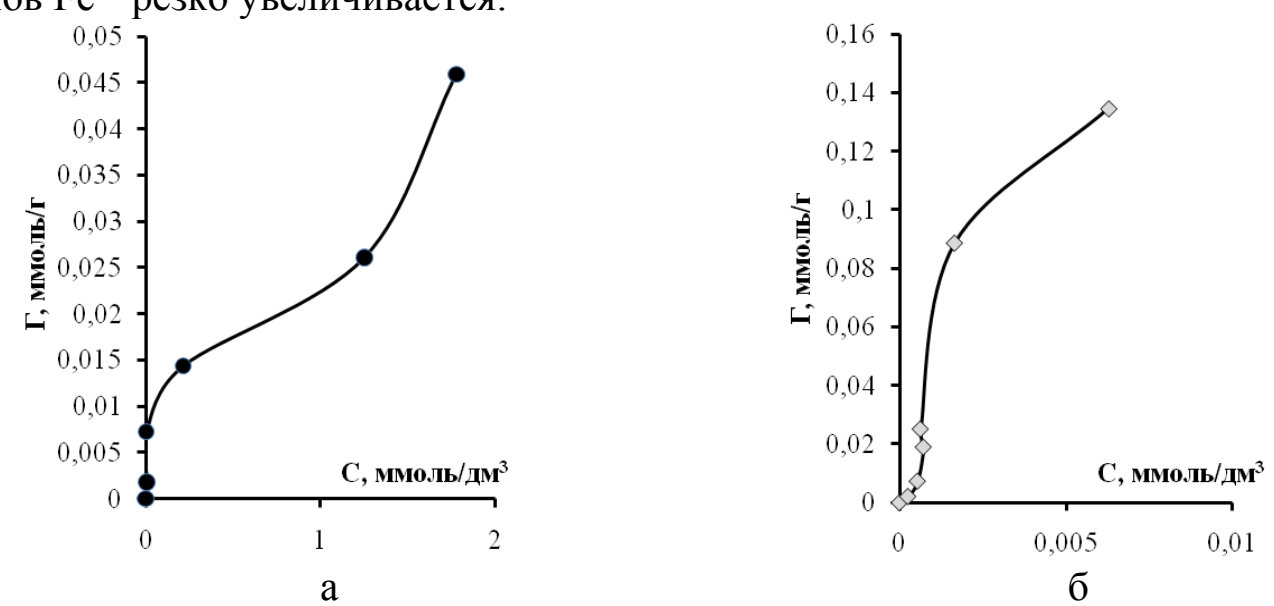

Рис. 2. Изотермы сорбции катионов $\mathrm{Fe}^{3+}$ : а - доломит нативный; б - доломит десятипроцентной добавкой ДКТ

В растворах (до и после контакта раствора с сорбентом) определяли значение водородного показателя (рис. 3). Во всех исходных растворах $\mathrm{pH}$ меньше 7, т. е. в исходных растворах хлорида железа (III) среда кислая. С увеличением концентрации исходного раствора, $\mathrm{pH}$ растворов уменьшается. Кислую среду в исходных растворах солей железа можно объяснить за счет реакции гидролиза катионов железа:

$$
\mathrm{Fe}^{3+}+\mathrm{H}_{2} \mathrm{O} \leftrightarrow \mathrm{FeOH}^{2+}+\mathrm{H}^{+}
$$

Соли железа(III) гидролизуются в большей степени, чем соли железа (II). C увеличением концентрации растворов $\mathrm{pH}$ исходных растворов изменяется незначительно. В присутствии сорбента с увеличением концентрации раствора $\mathrm{pH}$ исследуемых растворов уменьшается (рис. 3).

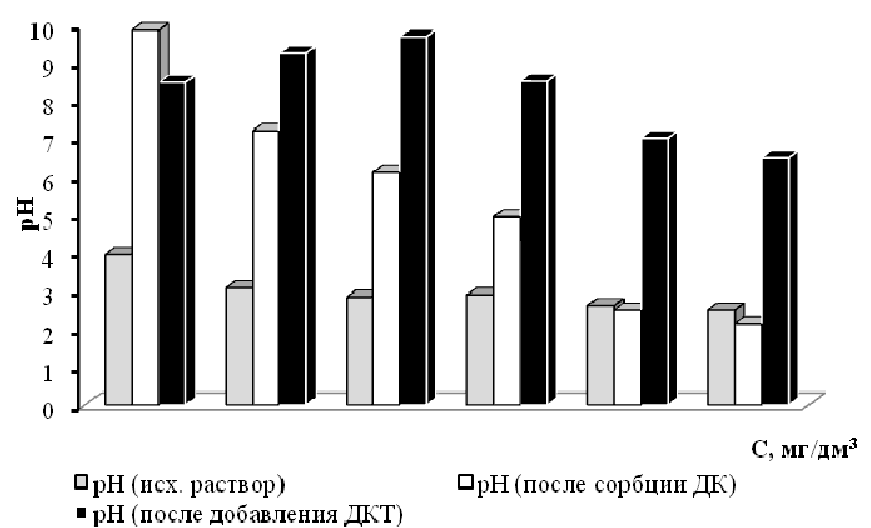

Рис. 3. Изменение величины $\mathrm{pH}$ раствора в зависимости от концентрации и типа сорбента

Присутствующий в растворе сорбент играет роль корректора $\mathrm{pH}$. В процессе термической обработки исходного доломита карбонат магния переходит в оксид $\mathrm{MgO}$, который имеет основные свойства. При прокаливании исходного доломита, используемого в качестве сорбента, изменился его состав. По результатам анализа можно предположить, что состав термически модифицированного сорбента (ДКТ) $4 \mathrm{CaCO}_{3} \cdot \mathrm{MgCO}_{3} \cdot 9 \mathrm{MgO}$. 


$$
\mathrm{CaCO}_{3} \cdot \mathrm{MgCO}_{3} \cdot \mathrm{MgO}(Д К) \stackrel{\text { Прамативаие }}{\longrightarrow} 4 \mathrm{CaCO}_{3} \cdot \mathrm{MgCO}_{3} \cdot 9 \mathrm{MgO} \text { (ДКТ) }
$$

Получившийся при прокаливании $\mathrm{MgO}$, может вступать во взаимодействие с водой, создавая щелочную среду:

$$
\mathrm{MgO}+\mathrm{H}_{2} \mathrm{O}=\mathrm{Mg}(\mathrm{OH})_{2} \leftrightarrow \mathrm{MgOH}^{+}+\mathrm{OH}^{-}
$$

Поэтому при добавлении к раствору прокаленного доломита резко повышается значение $\mathrm{pH}$ исследуемого раствора (рис. 3).

Катионы $\mathrm{Fe}^{3+}$ связывают ионы $\mathrm{OH}^{-}$, образуя менее растворимый и более слабый гидроксид железа(III). Равновесие смещается в сторону прямой реакции.

$$
3 \mathrm{Mg}(\mathrm{OH})_{2}\left(\Pi \mathrm{P}=6 \cdot 10^{-10}\right)+2 \mathrm{Fe}^{3+}=2 \mathrm{Fe}(\mathrm{OH})_{3}\left(\Pi \mathrm{P}=6,3 \cdot 10^{-38}\right)+3 \mathrm{Mg}^{2+} \text {. }
$$

Так как ионы $\mathrm{OH}^{-}$при этом образуют более устойчивое соединение, то их концентрация в растворе уменьшается, а $\mathrm{pH}$ раствора с увеличением концентрации $\mathrm{Fe}^{3+}$ в растворе уменьшается (рис. 3). Таким образом, с увеличением концентрации раствора хлорида железа (III), рН должен понижаться.

В опыте с доломитом для растворов с концентраций катионов $\mathrm{Fe}^{3+} 5$ мг/дм ${ }^{3}$ сразу после перемешивания раствора с сорбентом $\mathrm{pH}$ повышается на 6 единиц. С увеличением концентрации раствора уменьшается величина $\Delta \mathrm{pH}$ и степень очистки. Это понижение $\mathrm{pH}$ можно связать с тем, что соли магния подвергаются гидролизу с образованием кислой среды:

$$
\mathrm{Mg}^{2+}+\mathrm{H}_{2} \mathrm{O} \leftrightarrow \mathrm{MgOH}^{+}+\mathrm{H}^{+}
$$

В результате во всех исследуемых растворах при добавлении термически модифицированного сорбента или сорбента ДКТ скачок $\Delta \mathrm{pH}$ выше по сравнению с исходным доломитом и в связи с этим степень очистки растворов от катионов $\mathrm{Fe}^{3+}$ лучше.

При повышении исходной концентрации раствора хлорида железа(III) в процессе сорбции увеличивается общая жесткость раствора. Увеличение жесткости связано с увеличением концентрации катионов магния в растворе, а концентрация ионов кальция остается примерно на том же уровне (рис. 4)

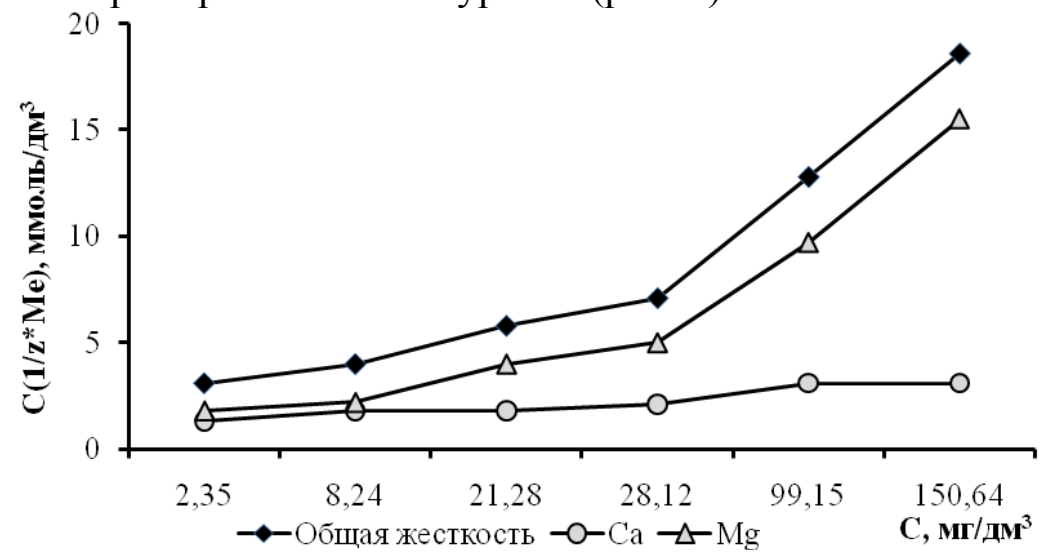

Рис. 4. Изменение общей жесткости и концентрации катионов кальция и магния в растворе после контакта с сорбентом в зависимости от концентрации соли железа в растворе

Ионы кальция и магния в растворе могут появляться и за счет ионообменной адсорбции. При обменной адсорбции сорбент, связывая определенное количество ионов из раствора, выделяет в раствор эквивалентное количество собственных ионов того же знака со своей поверхности. Суммарное количество эквивалентов ионов кальция и магния в растворе выше количества эквивалентов ионов железа адсорбированного доломитом. С увеличением концентрации исследуемого раствора соотношение количества моль эквивалентов ионов кальция и магния, (появившихся в 
растворе), к количеству моль эквивалентов железа, (ушедшим из раствора) уменьшается, изменяясь от 23 до 1.

$$
\left[v\left(\frac{1}{z} C a\right)+v\left(\frac{1}{z} M g\right)\right] / v\left(\frac{1}{z} F e^{+3}\right)
$$

В растворе хлорида железа(III) довольно кислая среда, поэтому катионы кальция и магния могут появляться и за счет взаимодействия сорбента с ионами водорода, что наиболее вероятно для исходных растворов с низкой концентрацией катионов $\mathrm{Fe}^{3+}$. В растворах с высокой концентрацией (100-150 мг/дм $\left.{ }^{3}\right)$ общая жесткость раствора примерно равна исходной концентрации железа (в моль/дм³) [7-9].

\section{Заключение}

По результатам исследования сорбционных свойств природного фильтрующего материала - доломита статическим методом можно сделать вывод, что в присутствии термически модифицированный добавки (нативный) доломит обладает более высокой адсорбционной способностью по отношению к катионам железа(III) по сравнению с исходным доломитом. Десятипроцентная добавка термически модифицированного доломита к исходному доломиту увеличивает степень очистки раствора от катионов $\mathrm{Fe}^{3+}$.

При использовании комбинированного сорбента или только термически обработанного доломита, массой всего 0.1 г, степень очистки раствора достигает значений ПДК для растворов с довольно высокой исходной концентрацией от 5 до

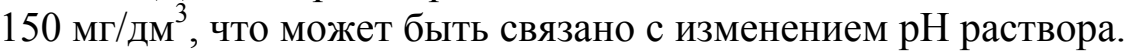

При исследовании процесса адсорбции катионов железа(III) из растворов на природных сорбентах опока, диатомит, доломит установлено, что все исследованные природные сорбенты обладают сорбционными свойствами по отношению к катионам железа(III). Опока характеризуется несколько более высокой адсорбционной способностью по сравнению с другими сорбентами. По величине адсорбционной способности по отношению к катионам железа(III) природные фильтрующие материалы можно расположить в ряд: опока > диатомит > доломит.

Термическая модификация опоки и диатомита не оказывает значительного влияния на их сорбционные свойства по отношению к катионам железа(III). Добавление $10 \%$ термически модифицированного доломита к нативным опоке и диатомиту резко увеличивает степень извлечения катионов железа(III) из исследуемых растворов.

Таким образом, комбинированный сорбент - нативный доломит, опока или диатомит с добавкой термически обработанного природного фильтрующего материала доломита обладает повышенной адсорбционной способностью, и позволяет получать более высокую степень очистки раствора. Поэтому при очистке воды от катионов $\mathrm{Fe}^{3+}$ лучше использовать комбинированные сорбенты.

\section{Список литературы}

1. Калюкова Е.Н., Иванская Н.Н. // Вестник Башкирского университета. 2011. Т. 16. №1. C. 25-28.

2. Калюкова Е.Н., Иванская Н.Н. // Башкирский химический журнал. 2013. Т.20. № 1. C. $115-119$.
3. Калюкова Е Н., Иванская Н.Н. Письменко В.Т. // Сорбиионные и хроматографические проиессы. 2010. Т. 10. № 2. С. 194-200.

4. Воропанова Л.А., Рубановская С.Г. // Экология и промышленность России. 1999. № 1. C. 44-47. 
5. Мандзий М.Р., Тарасова Ю.В., Шевченко Т.В. // Экология и промышленность России. 2003. №1. C. 35-37.

6. ПНД Ф 14.1:2.50-96 Количественный химический анализ вод. Методика выполнения измерений массовой концентрации общего железа в природных и сточных водах фотометрическим методом с сульфосалициловой кислотой.

7. Воюцкий С. С. Курс коллоидной химии. М. Химия. 1975.512 с.

\section{References}

1. Kaljukova E.N., Ivanskaja N.N., Vestnik Bashkirskogo universiteta, 2011., Vol. 16, No 1, pp. 25-28.

2. Kaljukova E.N., Ivanskaja N.N., Bashkirskij himicheskij zhurnal, 2013, Vol. 20, No 1, pp. 115-119.

3. Kaljukova E.N., Ivanskaja N.N. Pis'menko V.T., Sorbtsionnye i khromatograficheskie protsessy, 2010, Vol. 10, No 2, pp. 194-200.

4. Voropanova L.A., Rubanovskaja S.G., Jekologija i promyshlennost' Rossii, 1999, No 1, pp. 44-47.

5. Mandzij M.R., Tarasova Ju.V., Shevchenko T.V., Jekologija i promyshlennost' Rossii, 2003, No 1, pp. 35-37.

6. PND F 14.1:2.50-96 Kolichestvennyj himicheskij analiz vod. Metodika vypolnenija izme-

Нефедьева Татьяна Александровна - аспирантка 3 года обучения, Ульяновский государственный университет, Ульяновск

Калюкова Евгения Николаевна - к.х.н., доцент кафедры безопасности жизнедеятельности, экологии и химии, Ульяновский государственный технический университет, Ульяновск.

Благовещенская Нина Васильевна - д.б.н., профессор кафедры общей и биологической химии, Ульяновский государственный университет, Ульяновск
8. ПНД Ф 14.1:2. 98-97 Количественный химический анализ вод. Методика выполнения измерений жесткости в пробах природных и очищенных сточных вод титриметрическим методом.

9. Калюкова Е.Н., Нефедьева Т.А. «Актуальные вопросы и перспективы развития математических и естественных наук», Сборник научных трудов по итогам международной научно-практической конференции. Омск. 2016. С. 40-44.

renij massovoj koncentracii obshhego zheleza $\mathrm{v}$ prirodnyh i stochnyh vodah fotometricheskim metodom s sul'fosalicilovoj kislotoj.

7. Vojuckij S. S. Kurs kolloidnoj himii. Moskva, Himija, 1975, 512 p.

8. PND F 14.1:2. 98-97 Kolichestvennyj himicheskij analiz vod. Metodika vypolnenija izmerenij zhestkosti v probah prirodnyh i ochishhennyh stochnyh vod titrimetricheskim metodom.

9. Kaljukova E.N., Nefed'eva T.A. «Aktual'nye voprosy i perspektivy razvitija matematicheskih i estestvennyh nauk», Sbornik nauchnyh trudov po itogam mezhdunarodnoj nauchno-prakticheskoj konferencii (11 maja 2016 g.), Omsk, 2016, pp. 40-44.

Nefedyeva Tatyana A. - the postgraduate student of the 3st year of studies, Ulyanovsk State University, Ulyanovsk, e-mail: nefedeva.tatjana@mail.ru

Kaljukova Eugenia N. - Candidate of chemistry science, associate Professor of the Department of Safety, ecology and chemistry, Ulyanovsk state technical University, Ulyanovsk.

Blagoveshchenskya Nina V. - Ph.D. (biology), professor of department of general and biological chemistry, Ulyanovsk state university, Ulyanovsk 